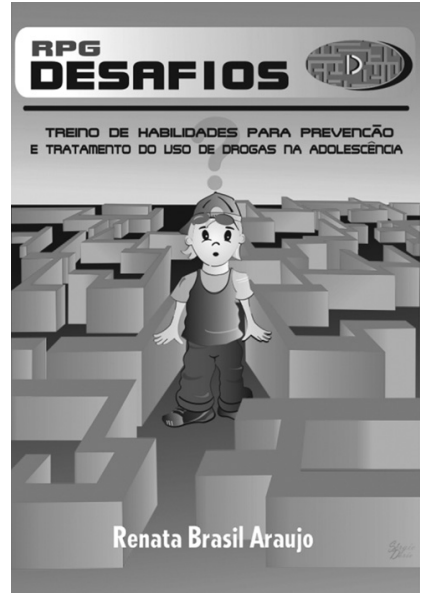

\title{
RPG Desafios: treino de habilidades para prevenção e tratamento do uso de drogas na adolescência
}

\author{
Renata Araújo, São Paulo, Vetor, 2009
}

\section{Maria Isabel Timm* \\ Um objeto gráfico múltiplo e interativo: potencial terapêutico e de pesquisa}

* Jornalista. Doutora em Informática na Educação. Coordenadora de Pesquisa e Desenvolvimento em Tecnologias Educacionais e Ensino a Distância, Centro Nacional de Supercomputação (CESUP), Universidade Federal do Rio Grande do Sul (UFRGS), Porto Alegre, RS.

Há quem diga que a adolescência é um truque da seleção natural para que os indivíduos realmente aptos consigam sobreviver àquele tormento e usufruir da maturidade. Outros, menos afeitos às reflexões, cunham novos termos, como aborrescentes, que mostram tanto o desconforto na relação com esses indivíduos quanto a distância que o falante quer manter em relação a um tempo ou uma parte do que certamente foi sua própria história. Renata Araujo encontrou uma forma original de representar a adolescência, respeitando sua complexidade, seus riscos, sua flexibilidade e o enorme potencial desconhecido - positivo e negativo - de cada adolescente, com que terapeutas, professores, pais e amigos muitas vezes não conseguem lidar, seja por desconhecimento, seja por falta de instrumentos objetivos de análise e de ação.

Renata conseguiu conceber e representar, de forma inteligente, realista e ao mesmo tempo carinhosa, essa situação explosiva e dinâmica. E porque conseguiu fazer isso, criou um instrumento de diagnóstico, intervenção e auto-orientação, que, por si, também é inovador e carregado de potencialidades. $\mathrm{O}$ conjunto representação-instrumento constitui uma espécie de objeto gráfico múltiplo e interativo, que excede o que seria um simples livro tanto quanto excede um simples jogo, caracterizando-se num verdadeiro manual de sobrevivência na vida cotidiana para adolescentes que precisam escolher entre estratégias realistas ou mágicas, avaliando a relação custo-benefício de cada uma delas de forma objetiva, através de uma quantificação de seu impacto sobre áreas de seu próprio perfil, como coragem, charme, força, inteligência, saúde ou simpatia.

Trata-se de uma caixa, contendo um manual de instruções de um jogo do tipo RPG (role playing game, jogo em que os jogadores assumem e interpretam papéis) e vários elementos gráficos - personagens, fichas de desafios, estratégias, locais e de anotações - para que os jovens se vejam em primeira pessoa e aos que os cercam, nos cenários que fazem parte de seu cotidiano, e atuem, de forma interativa, em situações familiares, escolares, sociais, etc. O conjunto chama-se RPG Desafios: treino de habilidades para prevenção e tratamento do uso de drogas na adolescência (editora Vetor, 2009). Mas também aí o jogo excede sua intenção - uso de drogas - e seu manuseio inclui situações que afligem os jovens dessa faixa etária, estejam eles ou não envoltos pela cultura das drogas, sejam elas legais ou ilegais.

Para jogar, os participantes devem escolher entre um conjunto de personagens, da faixa etária entre 14 e 16 anos, cujas fichas descrevem, em deliciosos desenhos acompanhados de pequenos textos coloquiais, gostos, características comportamentais e preferências (um é estudioso, outro odeia roupas da moda, outro é surfista, outra ainda quer ser pesquisadora no futuro, entre outros exemplos). Tais descrições, além de cobrir um grande espectro da personalidade das personagens e do seu comportamento social, quantificam as diferenças entre eles, através de notas às já referidas características (nota 8 para coragem, nota 9 para charme, por exemplo, sendo essas notas diferentes para cada um dos personagens). Com isso, abre-se a primeira janela para que o jogador olhe por ela e veja a si mesmo e seus amigos, com suas especificidades, seu mix de coisas boas, médias ou ruins, que ganham assim um tamanho e, portanto, um grau

\section{Correspondência:}

Maria Isabel Timm, Fernandes Vieira, 317/203, Bairro Bom Fim, CEP 90035-091, Porto Alegre, RS.

Não há conflitos de interesse associados à publicação desta resenha. 
de relevância na equação de potencialidades a desenvolver, ou dificuldades a enfrentar (a propósito, a atividade bem poderia ser usada por adultos que ainda desejem ou necessitem reconhecer as múltiplas facetas de sua personalidade e operar sobre comportamentos sociais, afetivos, etc.). Na verdade, esse equacionamento de lados de si mesmo e de outros já pode servir, de imediato, como ferramenta de autoconhecimento e de observação dos demais, independentemente de causas, culpas ou condicionantes socioeconômicos, ideológicos ou religiosos.

A dinâmica do jogo consiste em levar os participantes - investidos da persona descrita nas fichas dos personagens e, possivelmente, dos seus próprios sentimentos e comportamentos - a enfrentar desafios cotidianos. Esses desafios, como sabem todos aqueles que de alguma forma elaboraram e conscientizaram as vivências de sua própria adolescência, podem parecer banais, mas mobilizam um arsenal de defesas e ansiedades contra insegurança sobre suas próprias capacidades, medo do desconhecido, autoafirmação, curiosidade sobre a sexualidade, etc., todos eles potenciais gatilhos para soluções mágicas, como as drogas (tratadas no jogo como poções que ligam/desligam, ou que tornam a pessoa charmosa e a vida agradável). Por exemplo: para desafios do tipo "estar ameaçado de apanhar de colega", ou "ficar de castigo", "apresentar trabalho de aula para a turma inteira", ou ainda "amigos convidam para faltar à aula", cada personagem deverá avaliar estratégias como: "trocar de amizades", "lembrar que o problema não vai durar para sempre", "tomar Viajolin (poção mágica que faz a pessoa se sentir como se estivesse andando nas nuvens)", ou "dar uma caminhada enquanto pensa no problema". E antes que se pense em uma possível simplificação dessa dramática equação existencial adolescente, nos termos de uma programação do tipo se-isso/faça-aquilo, informe-se que: cada desafio - e cada estratégia de solução - propõe uma contabilidade variável para cada uma das características do perfil do personagem (coragem, charme, etc.). Além dessa soma de pontos variáveis para cada lado da personalidade, cada estratégia ainda oferece bônus - positivos ou negativos - que vão dando instrumentos concretos e dinâmicos para uma computação de perdas e ganhos, de cada parte do conjunto dinâmico daquele indivíduo. Para agregar valor a essa computação, os pontos acumulados dão direito a prêmios, da escolha do jogador (viagem, prancha de surf, etc.).

Renata transforma a decisão do adolescente em um sistema razoavelmente complexo, no qual pode identificar variáveis dinâmicas, algumas das quais são do desafio, outras são da estratégia escolhida para enfrentá-lo e outras são do próprio adolescente, às voltas com seus múltiplos e conflitantes lados disputando espaço em uma mente-cérebro ainda pouco experiente para conhecer e lidar com eles. Um humanista formado nas principais escolas da psicologia e da psicanálise do século XX se insurge, nesse momento da leitura, e reclama do que seria uma visão computacional do processo de decisão humana, da subjetividade descrita na forma de um enfrentamento de desafios com estratégias calcadas em perdas e ganhos, ou ressente-se de alguma referência a reflexões mais densas sobre o papel ou responsabilidade da educação ou da cultura nas escolhas. A esses, para além da psicologia cognitiva, área de referência da autora da obra, sugere-se a descoberta de autores contemporâneos, como o biólogo Richard Dawkins ${ }^{1}$, o cientista cognitivo Steven Pinker ${ }^{2,3}$ ou o filósofo Daniel Dennett ${ }^{4}$, que dimensionam o estudo da mente e do comportamento humanos no escopo da psicologia, da filosofia e da biologia evolucionistas, observando o processamento mental humano na sua forma natural, enquanto espécie, despida de paradigmas culturais. Sugere-se, ainda, a heresia de tentar compreender esta natureza humana pelos olhos de um pesquisador da inteligência artificial, como Marvin Minsky',2,3, que descreve a inteligência e os processos de decisão através da maquinaria necessária para fazê-la funcionar em autômatos ou softwares (algumas obras dos autores citados e da resenhista, sobre esses autores, estão referenciadas abaixo).

Além do diálogo direto - e, talvez, involuntário - de Renata Araujo com cientistas que ampliaram a dimensão do conhecimento sobre psicologia e cognição, é importante dimensionar o espaço que esse trabalho abre para a ampliação da área da pesquisa cognitiva (e atente-se aí não apenas para a clínica psicológica, mas também para as necessidades educacionais), uma vez que pode render várias abordagens e formas de observação, incluindo dissertações e teses, com diferentes possibilidades de metodologias de pesquisa e tratamento de dados (observação direta, simulações, cortes por gênero ou classe social, entre tantos outros).

Por fim, como uma espécie de cereja do bolo, o trabalho da autora constitui um roteiro praticamente pronto para o desenvolvimento de uma versão virtual do jogo, o qual, em si, pode vir a caracterizar-se como um objeto de pesquisa na área de informática na educação, ou tecnologia educacional aplicada às áreas de saúde (ambas as áreas em fase de estruturação acadêmica, nas principais universidades do Rio Grande do Sul). Um dos principais desafios da produção de games virtuais educacionais ou terapêuticos é exatamente a extração do conteúdo dos especialistas e sua adaptação para o cada vez mais promissor universo virtual dos jogos, com seus espaços de interatividade, escolha, gravação de dados, compartilhamento, além de uma prática que começa a ser explorada, sob o nome de realidade aumentada ${ }^{6}$, que nada mais é do que misturar o jogo virtual (em computadores, palmtops, celulares ou TV interativa) à realidade pessoal do jogador, coisa que o robusto objeto gráfico múltiplo e interativo de Renata e sua equipe tem todas as condições de realizar?.

\section{Referências}

1. Dawkins R. Selfish gene. Great Britain: Oxford University. 30th ed. 2006.

2. Pinker S. Tábula rasa. São Paulo: Companhia das Letras; 2004.

3. Pinker S. Como a mente funciona. São Paulo: Companhia das Letras; 1998.

4. Dennett D. A perigosa idéia de Darwin. Rio de Janeiro: Rocco; 1988.

5. Minsky M. The emotion machine: commonsense thinking, artificial intelligence and the future of human mind. New York: Simon \& Schuster. 2006.

6. Kopfer E. Augmented learning. Research and desig of móbile educational games. United Kingdom: MIT; 2008.

7. Timm MI, Rocha ACB, Schnaid F, Zaro MA, Chiaramonte M. A virada computacional da filosofia e sua influência na pesquisa educacional. Ciências \& Cognição (UFRJ). 2007;11:2-20. Disponível em: http://www.cienciasecognicao.org/pdf/v11/ m327161.pdf. Acessado mar 2009. 